\title{
ARTICLE miR-106a deficiency attenuates inflammation in murine IBD models
}

\author{
Megan R. Sanctuary ${ }^{1}$, Rick H. Huang ${ }^{1}$, Ashleigh A. Jones ${ }^{1}$, Marisa E. Luck ${ }^{1}$, Carol M. Aherne ${ }^{2}$, Paul Jedlicka ${ }^{3}$, Edwin F. de Zoeten ${ }^{1}$ and
} Colm B. Collins ${ }^{1}$

Pro-inflammatory cytokine TNFa antagonizes regulatory T cell (Treg) suppressive function with a measurable reduction of IL-10 protein secretion. Tregs are critical to suppress excessive immune activation, particularly within the intestine where high antigenic loads elicit chronic subclinical immune activation. Employing a TNFa-driven murine inflammatory bowel disease (IBD) model $\left(\mathrm{TNF}^{\triangle \mathrm{ARE} /+}\right)$, which mirrors the Treg expansion and transmural ileitis seen in Crohn's disease, we demonstrate that the TNFamediated loss of Treg suppressive function coincides with induction of a specific miRNA, miR-106a in both humans and mice, via NFKB promoter binding to suppress post-transcriptional regulation of IL-10 release. Elevation of miR-106a and impaired Treg function in this model recapitulate clinical data from IBD patients. MiR-106a deficiency promotes Treg induction, suppressive function and IL-10 production in vitro. MiR-106a knockout attenuated chronic murine ileitis, whereas T cell restricted deficiency of miR-106a attenuated adoptive transfer colitis. In both models, attenuated inflammation coincided with suppression of both Th1 and Th17 cell subset expansion within the intestinal lamina propria. Collectively, our data demonstrate impaired Treg suppressive function in a murine IBD model consistent with human disease and support the potential for inhibition of miR-106a as a future therapeutic approach to treat chronic inflammatory conditions including IBD.

Mucosal Immunology (2019) 12:200-211; https://doi.org/10.1038/s41385-018-0091-7

\section{INTRODUCTION}

Inflammatory bowel disease (IBD) currently affects $\sim 2.5$ million Europeans, though the incidence continues to increase. ${ }^{1}$ The current standard treatment, anti-tumor necrosis factor (TNFa) antibody therapy induces remission in less than $50 \%$ of IBD patients ${ }^{2,3}$ leaving an unmet need for newer therapeutics. Clinical and experimental data indicate that IBD persistence is primarily $\mathrm{CD}^{+}{ }^{+}$T cell-mediated. ${ }^{4}$

Regulatory T cells (Treg), defined by forkhead box P3 (FoxP3) expression represent a subset of immunosuppressive $T$ cells. ${ }^{5}$ While Tregs utilize a variety of suppressive mechanisms including cAMP and adenosine, secretion of the anti-inflammatory cytokine IL-10 is considered one of the primary mechanisms for limiting T cell proliferation (for review ref. ${ }^{6}$ ). The importance of IL-10 in preventing IBD is highlighted by spontaneous enterocolitis occurring in mice lacking IL-10 $70^{7}$ and IL-10 receptor polymorphisms correlating with early onset IBD. ${ }^{8}$ Paradoxically, numerous studies have demonstrated increased $\mathrm{CD}^{+}{ }^{+} \mathrm{FoxP}^{+} \mathrm{T}$ cells in the intestinal lamina propria of IBD patients which fail to attenuate disease, potentially due to impaired Treg suppressive function. ${ }^{9}$ Interestingly, the impairment in Treg function can be reversed by antiTNFa treatment, however, it is unclear if this is a direct consequence of TNFa blockade or due to the attenuation of intestinal inflammation. ${ }^{10}$ Nevertheless, impaired Treg function is believed to contribute to the pathogenesis of IBD.
To assess Treg suppressive function in a murine IBD model, we have employed the TNF ${ }^{\triangle A R E /+}$ mouse model of Crohn's disease (CD), a model in which $\mathrm{CD}^{+}$effector T cells play a central role. ${ }^{11}$ These mice express a single copy of a TNFa mutation which lacks the AU-rich element ( $\triangle \mathrm{ARE})$ controlling mRNA stability, leading to over-stabilized TNFa mRNA and systemic elevation of TNFa protein. ${ }^{12}$ This results in the spontaneous development of chronic transmural ileitis reminiscent of human $C D$ in its histological features and highlights the pivotal role played by TNFa in IBD pathogenesis. ${ }^{11,12}$ We hypothesize that the ability of TNFa to transiently impair Treg function, as has been described in both Crohn's disease and ulcerative colitis (UC), ${ }^{13}$ may be mediated through induction of selective microRNA (miRNA). Rather than on/ off regulation of genes, miRNA mediate subtle up and downregulation allowing for fine control of key biologic functions including IL-10 release. ${ }^{14}$ Despite limited clinical success, ${ }^{15}$ miRNA remain attractive therapeutic targets to modulate immune function in a more specific manner than current broad spectrum immunosuppressive therapies.

Here we examine the role of a select miRNA in regulating Treg suppressive function in the TNF ${ }^{\triangle \mathrm{ARE} /+}$ model. We hypothesize that disease induction and maintenance is promoted by impaired Treg function, given their role in preventing overactive inflammation. We first assessed Treg frequency at the peak of intestinal inflammation (between 8 and 12 weeks) along with their capacity




Colorado School of Medicine, Anschutz Medical Campus, Aurora, CO 80045, USA

Correspondence: Colm B. Collins (Colm.Collins@ucdenver.edu)

These authors contributed equally: Megan R. Sanctuary and Rick H. Huang
}

Received: 22 November 2017 Revised: 14 August 2018 Accepted: 6 September 2018

Published online: 16 October 2018 
$\mathbf{a}$



b



C






Fig. 1 Regulatory $\mathrm{T}$ cell expression during ileitis. a Flow cytometric analysis of the frequency of $\mathrm{CD}^{+} \mathrm{FoxP}^{+}$from the $\mathrm{spleen}(\mathrm{SP})$, mesenteric lymph node (MLN), and ileal lamina propria (LP) demonstrate a significant increase in Treg frequency at peak disease (8-12 weeks) in TNF $\mathrm{TNRE}_{+}$mice relative to WT. b The increased frequency was offset by a reduction in IL-10 producing CD4 ${ }^{+}$FoxP3 ${ }^{+}$Tregs in ilea of 8 Wk $\mathrm{TNF}^{\triangle \mathrm{ARE} /+}$ mice relative to WT littermates. c Treg accumulation was confirmed by Taqman real-time PCR measurement of the relative FoxP3 mRNA expression in ileal whole tissue with results expressed relative to $18 \mathrm{~S}$ or CD4. d PCR analysis of isolated CD4 $4^{+} \mathrm{CD} 25^{+}$Tregs from WT and $\mathrm{TNF}^{\triangle \mathrm{ARE} /+}$ mice indicated no significant difference in IL-10 mRNA. Results represent mean \pm SEM for three mice per group from three independent studies. ${ }^{*} P<0.05,{ }^{* *} P<0.01,{ }^{* * *} P<0.01$

to produce IL-10. We identified a candidate miRNA, miR-106a, that is elevated in IBD in response to TNFa, which targeted the IL-10 $3^{\prime}$ untranslated region. MiR-106a has recently been found to be elevated in serum of IBD patients correlating with disease severity, suggesting it may also serve as a useful biomarker for both $C D$ and UC. ${ }^{16}$ We confirmed that miR-106a was elevated in our murine model and that selective inhibition of miR-106a enhanced Treg function in vitro. Finally, we assessed the impact of miR-106a deficiency on inflammation in multiple IBD models using a miR106a-363 knockout mouse strain.

\section{RESULTS}

Expansion of impaired regulatory T cells during active disease Consistent with previously published data from 20-week-old mice, ${ }^{17}$ we demonstrated a significant increase in Treg frequency in the inflamed ileal lamina propria of $8-12$-week-old TNF ${ }^{\triangle A R E /+}$ mice relative to $\mathrm{WT}$ controls $(8.1 \pm 0.5$ to $15.5 \pm 1.9 ; P<0.01$; Fig. 1a), with similar findings in both the spleen and MLN. The increased frequency was offset by a reduction in $\mathrm{CD} 4^{+} \mathrm{FoxP} 3^{+} \mathrm{IL}-$ $10^{+}$positive cells $(44.4 \pm 3.1 \%$ to $32.6 \pm 3.9 \%$; $P<0.01$; Fig. $1 \mathrm{~b})$ in the inflamed LP which was not recapitulated in other tissues investigated. The increased Treg frequency seen by flow cytometry was corroborated by a $6.7 \pm 1.8$ fold increase in FoxP3 mRNA (relative to CD4 expression) within the TNF ${ }^{\triangle \mathrm{ARE} /+}$ ileum compared to WT (Fig. 1c). This increased FoxP3 expression was even greater when expressed relative to $18 \mathrm{~S}$ given the influx of $\mathrm{CD}^{+}{ }^{+} \mathrm{T}$ cells into the inflamed intestine. Thus, chronic ileal inflammation results in an increased frequency of $\mathrm{CD}^{+}{ }^{+} \mathrm{FoxP} 3^{+}$ Tregs with decreased IL-10 production. This increased frequency may reflect an attempt to offset the reduction in IL-10 production. Interestingly, expression analysis of isolated Tregs of WT and $\mathrm{TNF}^{\triangle \mathrm{ARE} /+}$ mice indicated no difference in IL-10 mRNA (Fig. 1d) 


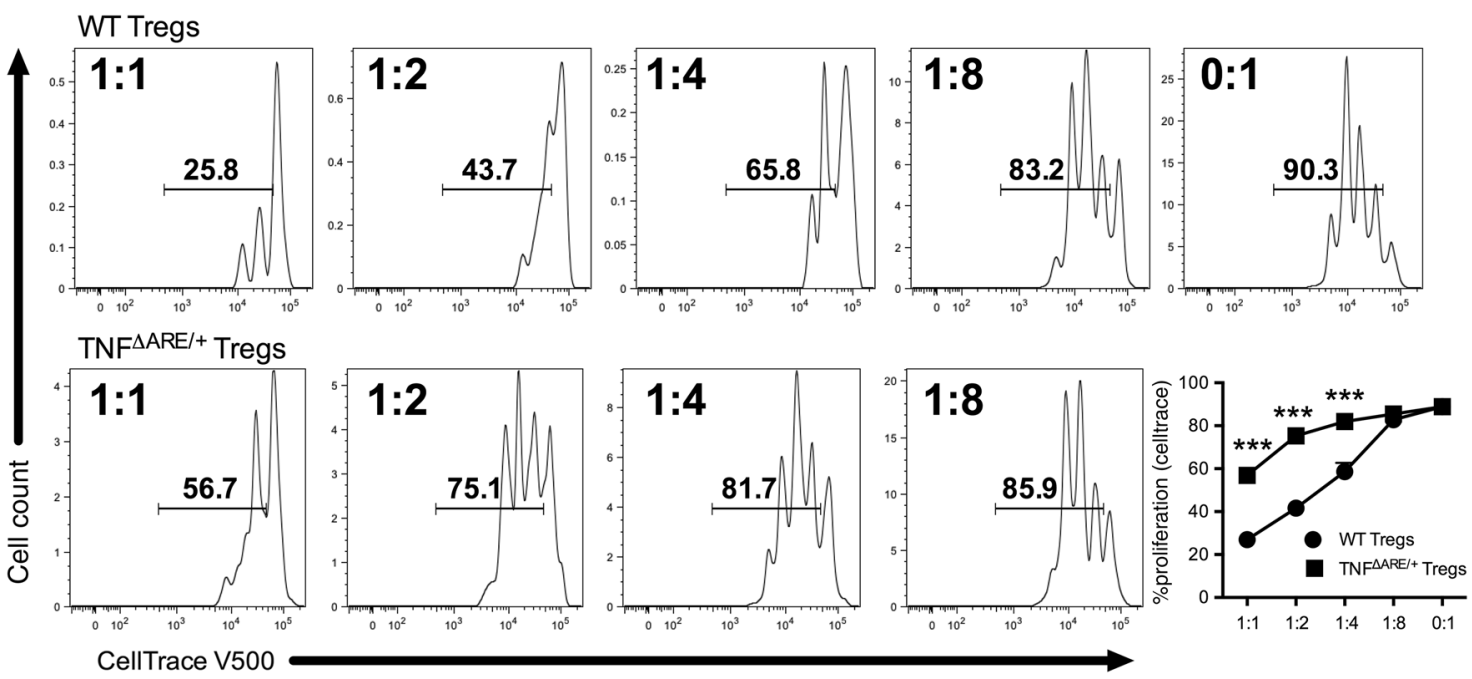

Fig. 2 Regulatory T cells from inflamed mice exhibit impaired suppressive function. Increasing ratios of isolated CD4 ${ }^{+} \mathrm{CD} 25^{+}$Tregs from both WT and $\mathrm{TNF}^{\Delta \mathrm{ARE} /+}$ mice were co-cultured with irradiated CD90 Neg antigen-presenting cells and fluorescent CellTrace-labeled effector cells stimulated with soluble anti-CD3 $(1 \mu \mathrm{g} / \mathrm{ml})$ for $72 \mathrm{~h}$. Proliferation of effector cells was quantified by flow cytometric analysis of the percentage of proliferating labeled lymphocytes as a surrogate marker of suppressive function. Tregs from TNF ${ }^{\Delta \mathrm{ARE} /+}$ displayed significantly weaker suppression of proliferation compared to WT littermates. Results represent mean \pm SEM for four technical replicates from three independent studies. ${ }^{* * *} P<0.001$

suggesting that the reduced IL-10 production was regulated at a post-transcriptional level.

Decreased suppressive function of Tregs from inflamed mice To assess the impact of reduced IL-10 output from Tregs on their suppressive function, we performed an in vitro Treg suppression assay. Magnetically isolated $\mathrm{CD} 4^{+} \mathrm{CD} 25^{+}$Tregs from TNF ${ }^{\triangle \mathrm{ARE} /+}$ mice were less suppressive compared to Tregs from WT littermates (Fig. 2; $P<0.001$ ) with significant increases in the frequency of proliferating effectors seen at 1:1 (56.9 $\pm 1.1 \%$ to 26.9 $\pm 0.9 \% ; P<0.001), 1: 2(75.3 \pm 1.2 \%$ to $41.7 \pm 3.0 \% ; P<0.001)$, and $1: 4$ ratios $(82.0 \pm 1.1 \%$ to $58.6 \pm 4.1 \% ; P<0.001)$. Supplementation of $\mathrm{IL}-10$ provided only partial recovery of $\mathrm{TNF}^{\triangle \mathrm{ARE} /+}$ Treg suppressive function (Supplemental Fig. 1), indicating that additional suppressive mechanisms may play a role. Taken together, the reduction in IL-10 production and increased effector $\mathrm{T}$ cell proliferation support the hypothesis that Tregs from $\mathrm{TNF}^{\triangle \mathrm{ARE} /+}$ are functionally impaired, which may represent a key mechanism perpetuating chronic inflammatory disease.

TNFa suppresses IL-10 production through a post-transcriptional mechanism

To examine the impact of recombinant TNFa on Treg IL-10 production, we employed the IL-10 IRES-GFP reporter strain to allow real-time monitoring of IL-10 transcription with stoichiometric GFP production. ${ }^{18}$ This demonstrated no significant difference when recombinant TNFa was added to culture media (Fig. 3a, b). This was further validated by harvesting RNA from isolated $\mathrm{CD}^{+}{ }^{+} \mathrm{CD} 25^{+}$Treg following $24 \mathrm{~h}$ incubation with TNFa and assessment of IL-10 by Taqman real-time PCR which also showed no significant difference (not shown). In contrast, ELISA of supernatants from these cultures were consistent with previous intracellular cytokine staining, showing that adding TNFa to WT Treg cultures resulted in reduced IL-10 secretion $(301.8 \pm 35.7 \mathrm{pg} /$ $\mathrm{ml}$ vs. $857.4 \pm 74.3 \mathrm{pg} / \mathrm{ml} ; P<0.00 ;$ Fig. 3c). Similarly, Tregs isolated from $\mathrm{TNF}^{\triangle \mathrm{ARE} /+}$ mice produced significantly less IL-10 relative to WT controls $(292.6 \pm 7.4 \mathrm{pg} / \mathrm{ml}$ vs. $857.4 \pm 74.3 \mathrm{pg} / \mathrm{ml} ; P<0.001$; Fig. 3c) yielding a similar output to that of WT Tregs challenged with TNFa in vitro. Interestingly, TNFa antibody blockade partially restored IL-10 output in TNF ${ }^{\triangle A R E /+}$ Tregs, $(518.1 \pm 26.3 \mathrm{pg} / \mathrm{ml}$ vs. $292.6 \pm 7.4 \mathrm{pg} / \mathrm{ml} ; P<0.001$; Fig. 3c). Taken together, these data support the ability of TNFa to modulate IL-10 protein secretion. We therefore assessed the impact of proteasomal inhibition on the secretion of IL-10 by Tregs from WT and TNF ${ }^{\triangle \mathrm{ARE} /+}$ mice. Treatment with the proteasomal inhibitor (MG132, $1 \mu \mathrm{M})$ significantly increased detectable levels of IL-10 in supernatants from WT $(435.0 \pm 20.1 \mathrm{pg} / \mathrm{ml}$ vs. $374.5 \pm 16.5 \mathrm{pg} / \mathrm{ml} ; P<0.05 ;$ Fig. $3 \mathrm{~d})$ but not TNF ${ }^{\triangle A R E /+}$ Tregs. Thus, the TNFa mediated decrease in IL-10 secretion was not altered by inhibition of the proteasome suggesting an alternative mechanism for the regulation of IL-10 production. To identify a mechanism of IL-10 post-translational modification that may account for the TNFa-dependent changes, we turned our attention to miRNA, short sequences of ribonucleotides that act as post-transcriptional regulators by binding to complementary sequences on target mRNA, resulting in translational repression or target degradation and gene silencing. ${ }^{19} \mathrm{~A}$ candidate miRNA had to be upregulated by $\mathrm{TNFa}^{20}$ known to downregulate $\mathrm{IL}-10,{ }^{14}$ be downregulated upon conversion to Tregs $^{21}$ and also be upregulated in human IBD. ${ }^{22}$ Based on these criteria, one particular miRNA (miR-106a) stood out as a suitable target for modifying Treg function in the $\mathrm{TNF}^{\triangle \mathrm{ARE} /+}$ model. Our studies validated the upregulation of miR-106a expression in isolated FoxP3-GFP ${ }^{+}$Tregs from TNF ${ }^{\triangle A R E /+}$ mice relative to WT littermates, which provides a rationale for targeting miR-106a suppression to enhance IL-10 production (Fig. 3e). Thus, TNFa appears to drive post-transcriptional suppression of IL-10 secretion independently of proteasomal degradation, implicating miR$106 a$ in this process. This may also point to an additional therapeutic mechanism of action of anti-TNFa antibodies.

\section{MiR-106a promoter activity depends on NFKB binding}

To confirm TNFa was capable of regulating miR-106a expression in human T cells, Jurkat cells were treated with recombinant TNFa. We observed a concentration-dependent increase in miR-106a expression with a significant increase observed with $10 \mathrm{ng} / \mathrm{ml}$ TNFa $(3.3 \pm 0.2$ fold induction; $P<0.01$; Fig. $4 a)$, consistent with murine $T$ cell data. Interestingly, TGF $\beta$ significantly suppressed miR-106a expression in a concentration-dependent manner with the greatest suppression seen at $10 \mathrm{ng} / \mathrm{ml}(0.18 \pm 0.01$ fold expression relative to control; $P<0.001$; Fig. 4a). This suggests that miR-106a is critical for pro-inflammatory signaling to transiently impair immunosuppressive signaling and may also 
a

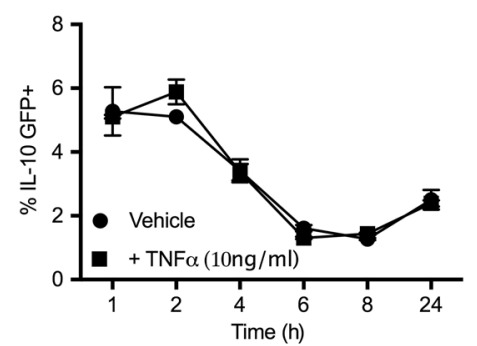

C

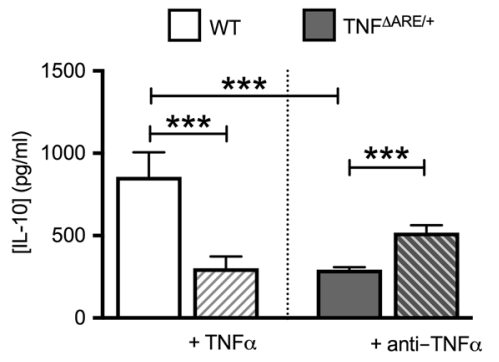

e



b



d



Fig. 3 Regulatory T cell IL-10 expression during inflammation. a Flow cytometric analysis of IL-10 mRNA in Tregs from IL-10 IRES-GFP reporter mice treated $\pm \mathrm{TNF} \alpha(10 \mathrm{ng} / \mathrm{ml})$ demonstrates no significant difference in IL-10 mRNA transcription. $\mathbf{b}$ Representative histogram showing the GFP-positive IL-10 reporter cells. c ELISA quantification of IL-10 production following $24 \mathrm{~h}$ treatment with anti-CD3/CD28 stimulation of isolated $\mathrm{CD}^{+} \mathrm{CD}^{2} 5^{+}$Tregs from WT and $\mathrm{TNF}^{\Delta \mathrm{ARE} /+}$ mice treated in vitro with either TNF $\alpha(10 \mathrm{ng} / \mathrm{ml})$ or anti-TNF $\alpha$ antibody $(10 \mu \mathrm{g} / \mathrm{ml}$; CNTO5048). d ELISA quantification of IL-10 production following $24 \mathrm{~h}$ treatment with MG132 $(1 \mu \mathrm{M})$ demonstrated that the decreased IL-10 production seen in $\mathrm{CD}^{+} \mathrm{CD} 25^{+}$Tregs from $\mathrm{TNF}^{\triangle \mathrm{ARE} /+}$ mice was not restored by inhibition of proteasomal degradation. e Real-time PCR validation of miR-106a expression by isolated $C D 4{ }^{+} \mathrm{CD} 25^{+}$Tregs from WT and TNF ${ }^{\triangle \mathrm{ARE} /+}$ mice. Results represent mean $\pm \mathrm{SEM}$ for three mice per group from three independent studies. ${ }^{*} P<0.05,{ }^{* * *} P<0.001$

have an important physiological role in Treg induction by TGF $\beta$. To assess if TNFa and TGF $\beta$ are directly targeting miR-106a transcription we used a dual luciferase reporter assay with the human miR-106a promoter in Jurkat cells. Previous studies have identified a putative promoter region on human chromosome $X$ for miR-106 $a^{23}$ and so we aimed to confirm the ability of TNFa and TGF $\beta$ to target this miR-106a promoter. TNFa caused a concentration-dependent induction of miR-106a promoter luciferase activity relative to Renilla luciferase $(4.4 \pm 0.01 \mathrm{RLU}$ with $10 \mathrm{ng} /$ ml TNFa treatment; $P<0.001$; Fig. 4b). In contrast, TGF $\beta$ suppressed miR-106a promoter luciferase activity in a concentration-dependent manner which was greatest at $10 \mathrm{ng} /$ $\mathrm{ml}$ of TGF $\beta(0.7 \pm 0.01$ fold induction relative to vehicle control; $P<0.01$; Fig. 4b). To identify potential sites on the miR-106a promoter that are responsive to TNFa signaling, we generated a number of promoter truncation mutants in arbitrary iterations of $250 \mathrm{bp}$. Both the full-sized construct and the $750 \mathrm{bp}$ truncation mutant retained a significant TNFa responsiveness $(P<0.001$; Fig. 4c) which was lost at $500 \mathrm{bp}$, suggesting that the putative transcriptionally activity region of the promoter is between 500 and $1000 \mathrm{bp}$. Interestingly sequence analysis of this region identified a putative NFKB-binding site at position 975-984 and an AP-1 site at position 554-562 (Fig. 4d). To determine the relevance of NFKB transcription factors or AP-1 transcription factors binding to the miR-106a promoter as a result of TNFa signaling, we performed luciferase assays with the full-length miR106 a construct in the presence of a NFKB inhibitor, Bay 11-7082 (10 $\mu \mathrm{M}$; Sigma-Aldrich) and an AP-1 false substrate, c-JUN peptide $(100 \mu \mathrm{M}$; Tocris Bioscience) using $10 \mathrm{ng} / \mathrm{ml}$ of TNFa unless otherwise stated (Fig. 4e). While inhibiting AP-1 activity failed to impact TNFa-induced luciferase activity, NFKB inhibition abolished all TNFa-induced luciferase activity $(0.03 \pm 0.006 ; P<0.0001$; Fig. 4e) supporting a role for NFKB binding to the miR-106a promoter as a result of TNFa signaling. This effect appears to be selective for miR-106a as expression of other miR-106 family members (Fig. 4f) including miR-17, located on a paralogous cluster miR-17-92 cluster, miR-106b found on the miR-106b cluster and miR-18, expressed within the same miR-106a-363 polycistronic unit, were all downregulated with TNFa treatment. However, miR-18 failed to reach statistical significance, which is consistent with some shared regulation. This phenomenon was recapitulated in isolated healthy human peripheral blood $\mathrm{CD}^{+}$ T cells in which paired analysis demonstrated a significant increase in miR-106a in response to TNFa treatment $(1.8 \pm 0.2$ fold increase; $P<0.05$; Fig. 4g). Thus, under physiological conditions, TGF $\beta$ appears to suppress miR-106a to facilitate Treg induction. In contrast, under inflammatory conditions, TNFa appears to drive upregulation of miR-106a through NFKB-dependent induction of the miR-106a promoter leading to temporary suppression of normal immune regulation. 



c



$\square$ Vehicle

$\operatorname{TNF} \alpha(10 \mathrm{ng} / \mathrm{ml})$



d

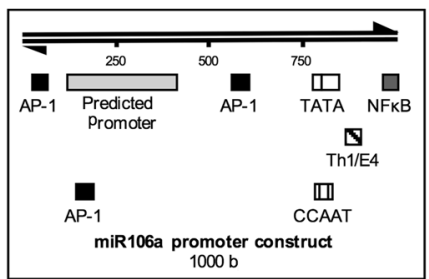

$\mathbf{f}$

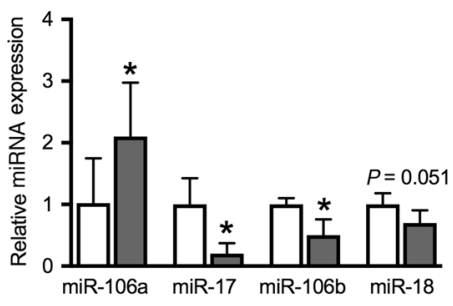

MiR-106a deficiency enhances Treg induction and function Germline deletion of the miR-106a-363 cluster significantly reduced the induction of $\mathrm{IFNy}^{+}$(Fig. 5a) cells and $\mathrm{IL}-17^{+} \mathrm{T}$ cell (Fig. 5b) from $\mathrm{CD}^{+}{ }^{+} \mathrm{CD} 25^{\mathrm{Neg}}$ splenocytes under Th0 conditions e
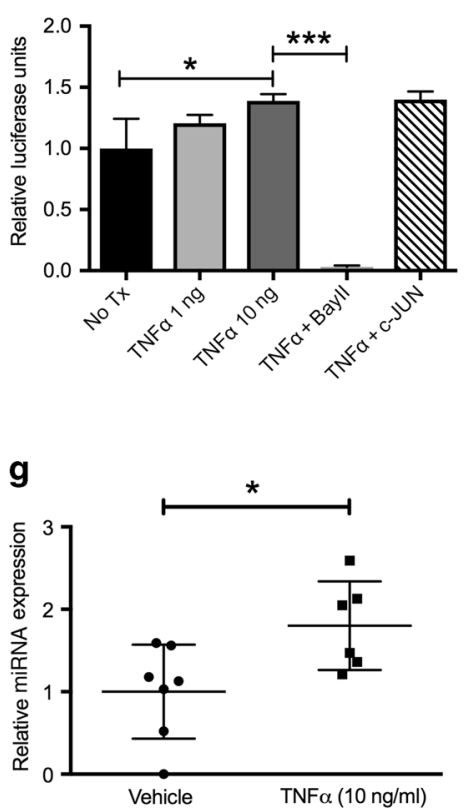

relative to WT cells. In contrast, the frequency of $\mathrm{CD}^{+}{ }^{+} \mathrm{FoxP}^{+}$ $\mathrm{T}$ cells induced under both Th0 and Tr1 conditions was significantly increased in cells from miR-106a $a^{-/-}$mice relative to WT controls (Fig. 5c). Increased Treg induction coincided with an 
Fig. 4 MiR-106a expression and promoter activity are induced by TNF $\alpha$. a Real-time PCR quantification of miR-106a expression from Jurkat T cells demonstrated induction of miR-106a ( $3.3 \pm 0.02$ fold) when treated with $10 \mathrm{ng} / \mathrm{ml}$ TNF $\alpha$ and contrasting concentration-dependent suppression of miR-106a expression $(0.18 \pm 0.01$ fold) relative to control when treated with $10 \mathrm{ng} / \mathrm{ml}$ of TGF $\beta$. b The impact of TNF $\alpha$ and TGF $\beta$ treatment on miR-106a transcription was mirrored in the putative miR-106a promoter reporter luciferase activity compared to Renilla luciferase. c Studies using promoter truncation mutants suggested that the putative TNF $\alpha$ responsive target site may fall between 500 bp and $1000 \mathrm{bp}$ on the miR-106a promoter, though results for the $250 \mathrm{bp}$ mutant suggested that in the absence of that region an alternative site may also exist. d Sequence analysis identified putative AP-1 and NFKB-binding sites within the miR-106a promoter region of interest. e Luciferase activity from the full-length miR-106a promoter reporter was abolished by incubation with the NFKB inhibitor Bay 11-7082 (10 $\mu \mathrm{M})$ but was unaffected by incubation with c-JUN peptide $(100 \mu \mathrm{M})$. $\mathbf{f}$ Expression analysis of miR-106a-associated miRNA from Jurkat T cells treated with $10 \mathrm{ng} / \mathrm{ml}$ TNF $\alpha$. g Expression of miR-106a by isolated healthy human CD4 ${ }^{+}$T cells treated for $6 \mathrm{~h}$ with vehicle or $10 \mathrm{ng} / \mathrm{ml}$ TNF $\alpha$. Results represent mean \pm SEM for four technical replicates from three independent studies. Human studies were performed on seven patients per group. ${ }^{*} P<0.05,{ }^{* *} P<0.01,{ }^{* * *} P<0.001$

increased expression of IL-10 (Fig. 5d). However, fold change analysis demonstrated that under Th0 conditions, the increased frequency of IL-10 producers present in miR-106a ${ }^{-/-}$cells, while preferentially occurring in Tregs, was also present in non-Tregs (Fig. 5e). Given the impaired Treg function seen in TNF ${ }^{\triangle A R E /+}$ mice, we next assessed in vitro suppressive function of Tregs from miR-106a ${ }^{-1} \mathrm{TNF}^{\triangle \mathrm{ARE} /+}$ mice relative to $\mathrm{TNF}^{\triangle \mathrm{ARE} /+}$ (Fig. 5f). miR$106 \mathrm{a}^{-1-} \mathrm{TNF}^{\triangle \mathrm{ARE} /+}$ Tregs displayed significantly greater suppressive function. However, this enhanced suppressive function was unaffected by IL-10R blockade, suggesting that even in the absence of IL-10 signaling miR-106a deficiency improves suppression (Fig. 5g). Because the miR-106a-363 knockout affects multiple miRNA, we validated the role of miR-106a in Treg suppressive function using a lentiviral approach. Lentiviral suppression of miR106 a significantly increased IL-10 secretion into cell culture supernatants measured by ELISA $(192.7 \pm 21.0 \mathrm{pg} / \mathrm{ml}$ vs. $130.8 \pm$ $9.8 \mathrm{pg} / \mathrm{ml} ; P<0.05$; Supplemental Fig. $2 \mathrm{~A}, \mathrm{~B})$ and corresponded to an increase in IL-10 secretion from miRZIP106a-transfected CD4 ${ }^{+}$ cells $(10.5 \pm 0.4 \%$ vs. $6.5 \pm 0.1 \% ; P<0.001$; Supplemental Fig. $2 \mathrm{C}$ ) measured by intracellular cytokine staining. While converted Tregs were less suppressive than their freshly isolated counterparts (not shown), miRZIP106a transduced Tregs demonstrated significantly improved Treg suppressive function relative to Tregs transduced with the control vector (Supplemental Fig. 2E) at 1:1 Treg:Teffector ratio $(24.8 \pm 2.4 \%$ vs. $36.1 \pm 3.8 \% ; P<0.05)$ and $1: 4$ Treg ratio $(52.9$ $\pm 0.6 \%$ vs. $55.3 \pm 0.7 \%$; $P<0.05)$. Taken together, miR-106a induction appears to be at least one mechanism by which TNFa reduces IL-10 production and impairs Treg suppressive function.

MiR-106a deficiency suppresses T cell colitogenic potential Employing the same miR-106a $\mathrm{a}^{-/-}$strain, we demonstrated attenuated adoptive transfer colitis when naive $\mathrm{CD}^{+} \mathrm{CD} 45 \mathrm{RB} \mathrm{B}^{\mathrm{High}}$ $\mathrm{T}$ cells from miR-106a ${ }^{-/-}$mice were transferred to a lymphopenic $\mathrm{RAG}^{-1-}$ host relative to WT controls (Fig. 6a) as evidenced by a decrease in weight loss (Fig. 6b) and a reduction in the frequency of IFN ${ }^{+}$(Fig. 6C) and IL- $17^{+} \mathrm{CD} 4 \mathrm{~T}$ cell (Fig. 6d) infiltration into the colonic lamina propria. Interestingly, there was a small reduction in IL-10 producing T cells within the lamina propria also though this may reflect a decreased inflammatory state (Fig. 6e). Taken together, these data suggest that miR-106a ${ }^{-1-} \mathrm{CD} 4^{+} \mathrm{T}$ cells have reduced colitogenic potential compared with $\mathrm{WT}$.

miR-106a deficiency attenuated TNFa-driven intestinal inflammation in vivo

To validate our colitis findings in a second preclinical IBD model, we crossed miR-106a ${ }^{-1-}$ mice to the $\mathrm{TNF}^{\triangle \mathrm{ARE} /+}$ chronic murine ileitis model. We demonstrate a significant attenuation of histological indices of ileitis (Fig. 7a, b) including active inflammatory index (indicative of granulocytic infiltration), chronic inflammatory index (indicative of lymphocytic infiltration), villus distortion (inflammation-associated villus blunting), and total inflammatory indices $(P<0.05 ; n=9-14$ mice/genotype) in $8-12$-week-old miR-106a ${ }^{-/} \mathrm{TNF}^{\Delta \mathrm{ARE} /+}$ mice relative to $\mathrm{TNF}^{\triangle \mathrm{ARE} /+}$ controls. Consistent with colitis experiments, the decreased ileitis in miR-106a $a^{-/-} \mathrm{TNF}^{\triangle \mathrm{ARE} /+}$ mice coincided with a reduction in the frequency of $\mathrm{IFNY}^{+}$(Fig. 7c) cells and $\mathrm{IL}-17^{+}$ $\mathrm{T}$ cell (Fig. $7 \mathrm{~d}$ ) infiltration into the ileal lamina propria. Once again, we observed a reduction in IL-10-producing $T$ cells within the lamina propria likely reflecting a decreased inflammatory state (Fig. 7e). This effect is unlikely to be the result of impaired gut homing of miR-106a $\mathrm{a}^{-/-} \mathrm{CD} 4^{+} \mathrm{T}$ cells to the inflamed intestine as competitive homing assays indicated no significant difference in homing between WT and miR-106a ${ }^{-/-}$cells (Supplemental Fig. 3). Taken together, these data suggest that miR-106a deficiency decreases susceptibility to spontaneous ileitis.

\section{DISCUSSION}

We have previously reported an increase in Treg frequency in the ileal lamina propria of chronically inflamed 20 -week-old TNF ${ }^{\triangle A R E /+}$ mice in the face of exacerbated inflammation. ${ }^{17}$ We now extend this finding to demonstrate that a similar induction is observed during the early stage of peak disease onset in this model at 8 weeks-of-age, which is consistent with data from patients with Crohn's disease who display a similar increase in Tregs within the inflamed ileum. ${ }^{9}$ This was counterintuitive, however, given an increase in an anti-inflammatory population would be expected to attenuate inflammation rather than facilitate it. We postulate the reason for this apparent paradox comes from understanding the impact of inflammation on Treg suppressive function. Under inflammatory conditions, pro-inflammatory cytokines acting via multiple mechanisms, including through TNFa receptors, can induce a transient resistance to suppression in effector $\mathrm{T}$ cells ${ }^{24}$ that allows rapid expansion of the effector $\mathrm{T}$ cell population to deal with the immediate insult before undergoing activationinduced apoptosis. Thus, it is not surprising that TNFa would be able to further amplify this effect by blunting Treg suppressive function. Consistent with that hypothesis, data from human studies of Treg function in IBD patients using anti-TNFa therapy demonstrate a concomitant improvement in Treg function. ${ }^{10,25,26}$

In our experiments, the increase in Treg frequency coincided with a reduction in IL-10 output in vivo and reduced in vitro suppressive function of Tregs from $\mathrm{TNF}^{\triangle \mathrm{ARE} /+}$ mice. Similar outcomes were seen if the proliferating cells were from inflamed $\mathrm{TNF}^{\triangle \mathrm{ARE} /+}$ mice or wildtype (not shown) suggesting a predominant defect in the TNF ${ }^{\triangle A R E /+}$ Tregs. The reduction in IL-10 output could be directly linked to TNFa, as treatment with an anti-TNFa antibody reversed the effect. Interestingly, the decrease in IL-10 output was not mediated by downregulation of IL-10 mRNA as demonstrated using IL-10 IRES-GFP reporter mice alongside realtime PCR. IL-10 production in vivo is highly regulated with excess IL-10 increasing susceptibility to infection ${ }^{27}$ and inadequate IL-10 signaling exacerbating IBD. ${ }^{8}$ As a result, a large number of regulatory mechanisms including $A U$-rich elements which control mRNA stability, stress-response factors, ${ }^{28}$ miRNA, suppressor of cytokine signaling 3 (SOCS3), nucleotide-binding oligomerization domain-containing protein two expression (NOD2) dysfunction of which is positively associated with IBD 

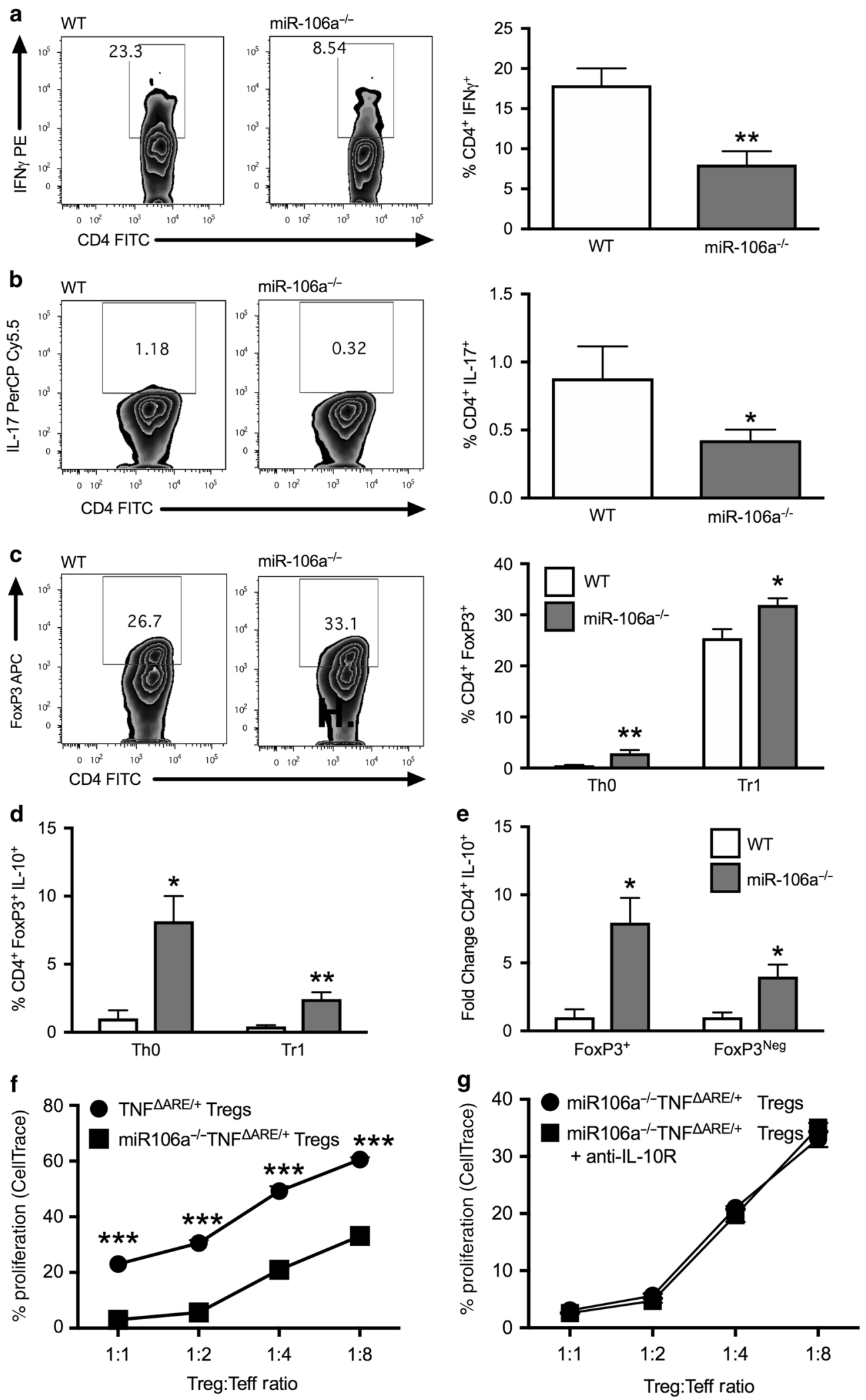

Fig. 5 MiR-106a deficiency promotes anti-inflammatory T cell induction. Under Th0 conditions, isolated CD4 ${ }^{+} \mathrm{CD} 25^{\mathrm{Neg}}$ cells from miR-106a ${ }^{-/-}$ mice displayed a significant decrease in expression of (a) IFN $\gamma$ and (b) IL-17 as well as an increase in (c) FoxP3 relative to WT controls. In the presence of TGF $\beta$, miR-106a ${ }^{-/-}$CD4 ${ }^{+} \mathrm{CD} 25^{\mathrm{Neg}}$ cells underwent significantly greater Treg conversion compared to WT (c) with greater IL-10

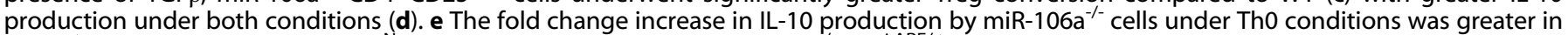
FoxP $3^{+}$but also occurred in FoxP ${ }^{\text {Neg }}$ cells. $f$ Isolated Tregs from miR-106a- $\mathrm{TNF}^{\Delta \mathrm{ARE} /+}$ mice displayed significantly greater in vitro suppressive function relative to $\mathrm{TNF}^{\triangle \mathrm{ARE} /+}$ alone. $\mathbf{g}$ Enhanced suppressive function was maintained with antibody blockade of IL-10R signaling. Results represent mean \pm SEM for four technical replicates from three independent studies. ${ }^{*} P<0.05,{ }^{* *} P<0.01,{ }^{* *} P<0.001$ 
a

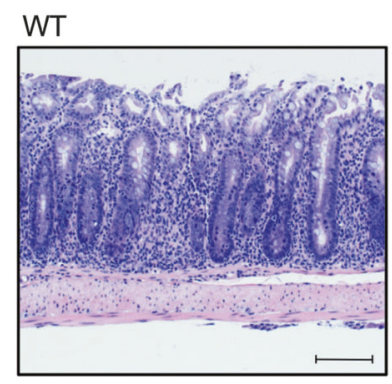

$\operatorname{miR}-106 a^{-1-}$

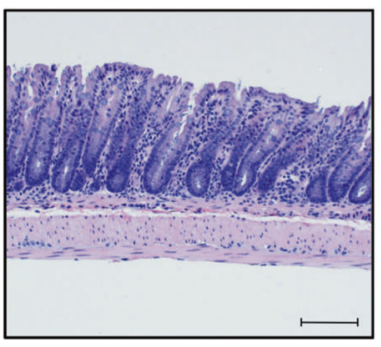

c

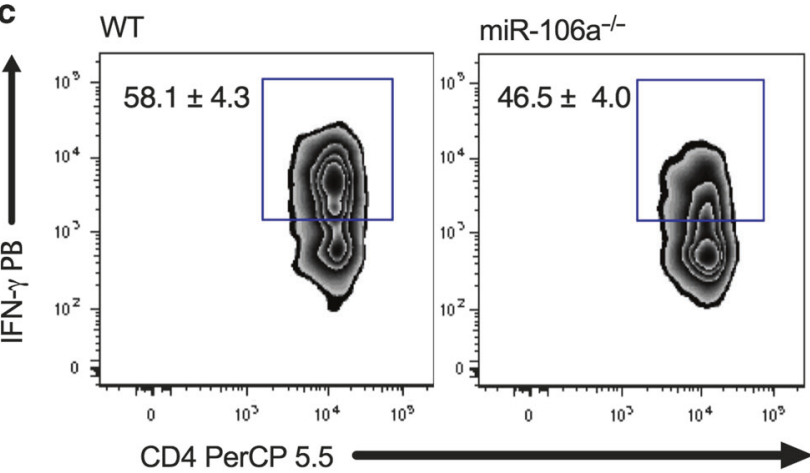

d

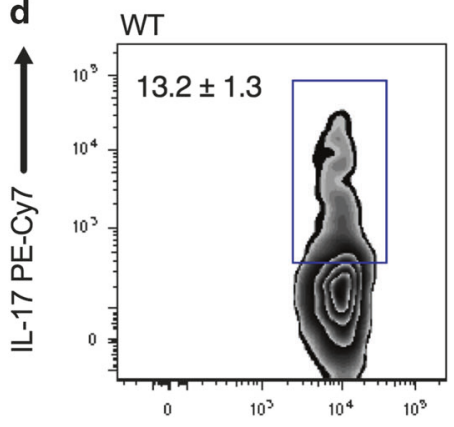

CD4 PerCP 5.5



b


Fig. 6 MiR-106a deficiency attenuates colitogenic T cell potential in vivo. a Histology of the colonic lamina propria demonstrates significant villus distortion in WT CD45RB High $\mathrm{T}$ cell recipients relative to miR-106a $\mathrm{a}^{-/-} \mathrm{T}$ cell recipients following adoptive transfer. $\mathbf{b}$ Adoptive transfer of $\mathrm{CD}^{+} \mathrm{CD} 45 \mathrm{RB}^{\text {High }} \mathrm{T}$ cells from miR-106a ${ }^{-/}$mice resulted in significantly attenuated weight loss, a surrogate marker of intestinal inflammation, relative to WT controls. This result coincided with a significant reduction in IFN $\gamma^{+} \mathrm{CD} 4^{+} \mathrm{T}$ cells $(\mathbf{c})$ and IL-17 ${ }^{+} \mathrm{CD} 4^{+} \mathrm{T}$ cells (d) in the colonic lamina propria as well as a reduction in IL-10-producing CD4 ${ }^{+}$T cells (e). Results represent mean \pm SEM for 4-7 mice per group from two or more independent studies. ${ }^{*} P<0.05,{ }^{* *} P<0.01,{ }^{* *} P<0.001$ 
a TNFAARE/+

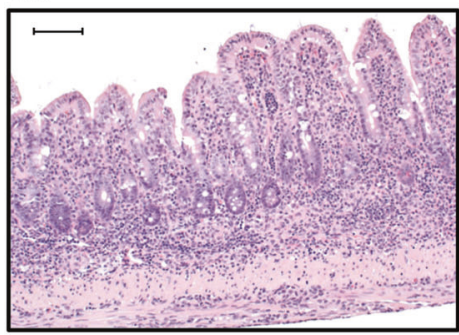

miR-106a $\mathrm{a}^{-1-T N F} \Delta \mathrm{ARE} /+$

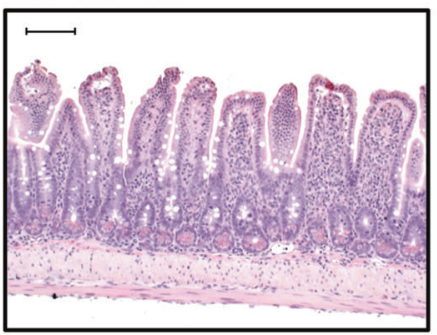

c $\mathrm{TNF}^{\triangle \mathrm{ARE} /+}$

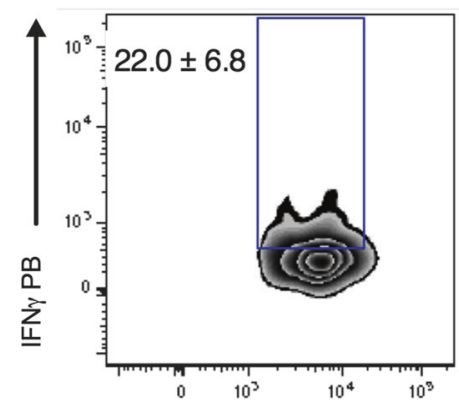

CD4 PerCP 5.5

d
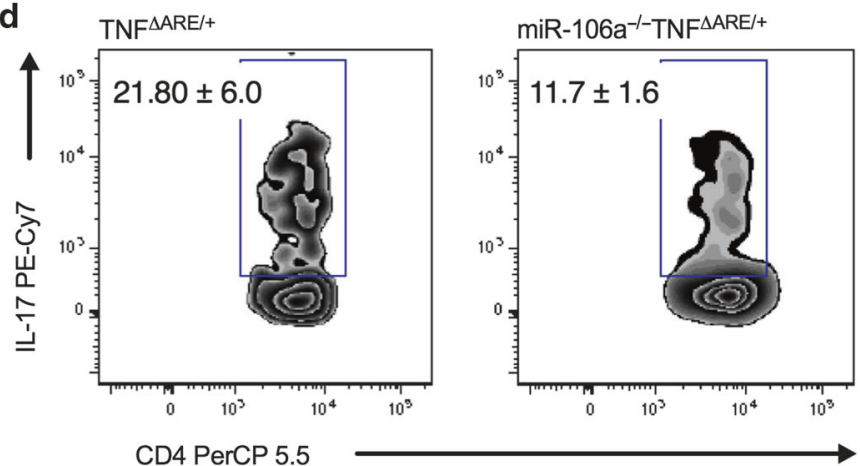

e



miR-106a- $a^{-1} \mathrm{TNF}^{\mathrm{AARE} /+}$

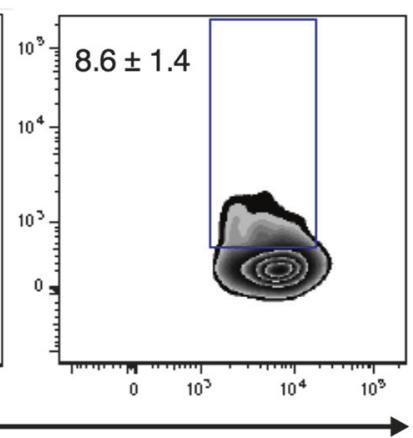

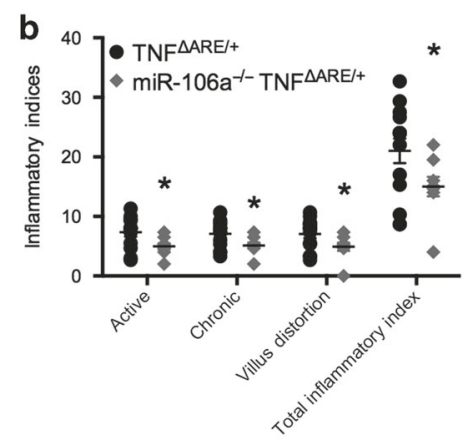
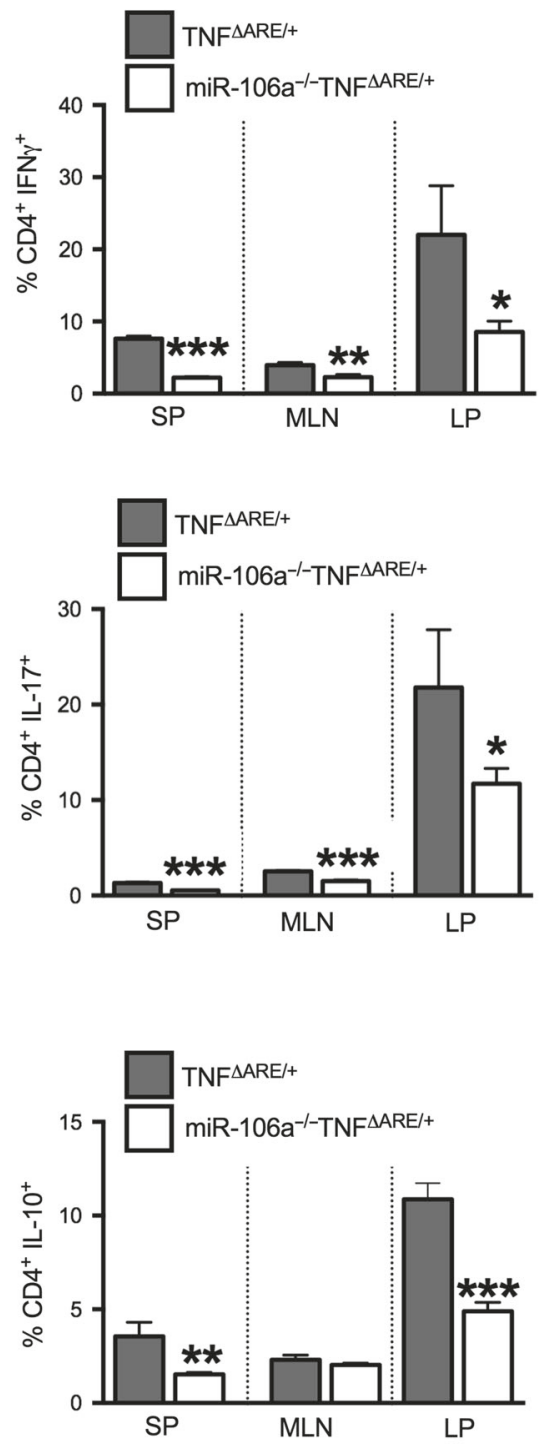

Fig. $7{\mathrm{MiR}-106 \mathrm{a}^{-/-} \text {mice display attenuated ileitis in vivo. Blinded histological evaluation of intestinal inflammation in the TNF }}^{\Delta \mathrm{ARE} /+}$ ileum demonstrated a significant decrease in acute and chronic inflammatory indices in addition to a reduction in villus distortion in


$\mathrm{CD}^{+} \mathrm{T}$ the ileal lamina propria of 8-12-week-old mice. Results represent mean \pm SEM for 4-7 mice per group from two or more independent studies. ${ }^{*} P<0.05,{ }^{* *} P<0.01,{ }^{* * *} P<0.001$

susceptibility $^{29}$ and IL-10 itself control IL-10 proteins levels (reviewed in ref. ${ }^{30}$ ).

In the absence of transcriptional regulation of IL-10 output, we chose to assess the potential for miRNA to provide the necessary modification of Treg function based on the established alterations in miRNA associated with IBD. Our search criteria for candidate miRNA were confined to miRNA induced by TNFa, that target and suppress IL-10 translation and are induced both in human IBD and in our murine model. Based on these restrictions, one particularly suitable candidate was identified, miR-106a. MiR-106a is 
upregulated in both $\mathrm{TNF}^{\mathrm{AARE} /+}$ Tregs as well as IBD tissues ${ }^{22}$ and known to negatively affect IL-10 production. ${ }^{14}$ Excitingly, miR$106 a$ also represents one of the few miRNA that are actually upregulated upon $T$ cell activation, while the majority of miRNA are downregulated. ${ }^{31}$

Previous promoter studies have focused on a region immediately upstream of miR-106a; ${ }^{14}$ however, because of how singlestranded miRNA are processed, promoters of miRNA are significantly further away (as much as $90 \mathrm{~kb}$ ) from the miRNA hairpin region. ${ }^{23}$ We validated the predicted miR-106a promoter region $^{23}$ and demonstrated it was not only induced by TNFa in an NFkB-dependent manner as previously reported but that it was also inversely affected by TGF $\beta$, consistent with a physiological role for miR-106a in Treg development. In addition, we demonstrated in vitro that miR-106a deficiency suppressed IFNy ${ }^{+}$Th1 and $\mathrm{IL}_{-1} 17^{+}$Th17 induction, while promoting FoxP3 ${ }^{+}$Treg induction, further supporting a role for TGF $\beta$-mediated miR-106a suppression in Treg development. This increased Treg conversion coincided with increasing IL-10 production in both Tregs and nonTregs. However, whether or not increased IL-10 output is responsible for improved Treg induction remains unclear. MiR106a deficiency also rescued Treg suppressive function in isolated Tregs from miR-106a ${ }^{-/} \mathrm{TNF}^{\triangle \mathrm{ARE} /+}$ mice relative to $\mathrm{TNF}^{\triangle \mathrm{ARE} /+}$. However, antibody-mediated IL-10 receptor blockade failed to reverse this improvement. Similar to the conversion studies, these results suggest that additional mechanisms targeted by miR-106a remain unidentified. In addition, we know that impaired IL-10 production is not the only dysfunction of Tregs impacting disease pathogenesis. Increased apoptosis $\mathrm{s}^{32}$ and IL-17 production by Tregs are also associated with IBD. ${ }^{33}$ Thus, while data from these studies support using miRNA-modification to enhance Treg function as a valid therapeutic approach for the treatment of IBD, this approach may be more successful if combined with additional miRNA.

Based on our in vitro data, we hypothesized that targeting the miR-106a cluster would attenuate intestinal inflammation in vivo. Initially, we examined the impact of miR-106a deletion on isolated $\mathrm{CD}^{+}{ }^{+} \mathrm{T}$ cell colitogenic potential. Using the well-established CD45RB ${ }^{\text {High }}$ colitis model ${ }^{34}$ we demonstrated for the first time that deletion of the miR-106a miRNA family in $\mathrm{CD}^{+}{ }^{+} \mathrm{T}$ cells resulted in attenuation of inflammation in lymphopenic recipients. This was characterized by a decrease in Th1 and Th17 cells known to perpetuate inflammation, along with a reduction in IL-10 producing $T$ cells, which are induced in response to inflammation to serve as a negative feedback mechanism. ${ }^{30}$ While the small but significant decrease in the percent of $\mathrm{CD}^{+} \mathrm{IL}-10^{+} \mathrm{T}$ cells in the colonic lamina propria of mice receiving miR-106a $a^{-1-} \mathrm{T}$ cells appears contrary to our hypothesis and data showing that miR106a-deficiency promotes IL-10 production, we also recognize that IL-10 can be produced by Th1 and Th17 cells and this decrease more than likely reflects the marked decrease in the frequency of those cells. ${ }^{30}$ We further validated these studies with similar findings in a second preclinical mouse model of IBD, the TNF ${ }^{\triangle \mathrm{ARE} /+}$ model of Crohn's disease. ${ }^{12}$ As with adoptive transfer colitis, this model is heavily CD4 ${ }^{+}$T cell dependent. ${ }^{11}$ Once again, miR-106a deficiency was associated with attenuation of intestinal inflammation. Based on recent evidence for a role for miR-106a-5P in renal cell migration, ${ }^{35}$ we also examined a potential deficit in lymphocyte gut homing that may have driven the attenuation in intestinal inflammation. However, our current studies showed no significant differences between miR-106a ${ }^{-/-}$and WT CD4 ${ }^{+} \mathrm{T}$ cell trafficking to the intestine.

While selectively targeting individual miRNA and delivering miRNA mimics or antagomirs remains a challenge to the adoption of miRNA targeting approaches, ${ }^{15}$ evidence from these studies clearly demonstrates for the first time the potential therapeutic use of miR-106a targeting for the treatment of inflammatory bowel disease. Unlike conventional therapies which offer only on/off type regulation, miRNA targeting may allow for more finetuning of the immune system.

\section{METHODS}

Mice

The B6.129S-Tnf ${ }^{\mathrm{tm} 2 \mathrm{GKI}} /$ Jarn strain $\left(\mathrm{TNF}^{\triangle \mathrm{ARE} /+}\right.$; MGI:3720980) was generated by continuous backcrosses between heterozygous $\mathrm{TNF}^{\triangle \mathrm{ARE} /+}$ on a mixed background ${ }^{12}$ to C57BL6/J mice ${ }^{11}$ and kept under specific pathogen-free conditions. Experimental animals were heterozygous for the $\triangle \mathrm{ARE}$ mutation $\left(\mathrm{TNF}^{\triangle \mathrm{ARE} /+}\right)$ or homozygous wildtype (WT), which served as controls. MiR-106a$363^{-1-}$ mice on the C57BL6/J background were obtained from Jackson Laboratories (\#008461, Bar Harbor, ME). MiR-106a-363 ${ }^{-/-}$ mice were crossed with B6.129P-Tnf ${ }^{\triangle A R E}\left(\mathrm{TNF}^{\triangle \mathrm{ARE} /+}\right)$ to produce miR-106a-363 ${ }^{-/-} / \mathrm{TNF}^{\triangle \mathrm{ARE} /+}$ mice. WT/FoxP3-green fluorescent protein (GFP) and $\mathrm{TNF}^{\triangle \mathrm{ARE} /+} / \mathrm{FoxP3-GFP}$ reporter strains were kindly provided by Dr. de Zoeten. IL-10 internal ribosomal entry site (IRES)-GFP reporter mice were provided by Dr. Eric Clambey (\#008379; Jackson Laboratories). Adoptive transfer colitis was induced by intraperitoneal injection of $1 \times 10^{6}$ cells/mouse of magnetically pre-enriched $\mathrm{CD}^{+}{ }^{+} \mathrm{T}$ cells (EasySEP, STEMCELL Technologies, Vancouver, $\mathrm{Ca})$ flow sorted into live $\mathrm{CD}^{+}$ $\mathrm{CD}_{4}$ RB $^{\text {High }}$ naive T cells (BD FACSAria II, BD Biosciences, Franklin Lakes, NJ). Fecal samples were negative for Helicobacter, protozoa and helminths. All animals were handled according to procedures approved by the institutional committee for animal use.

\section{Lymphocyte isolation}

Cells from indicated organs were isolated as previously described. ${ }^{36}$ Briefly, spleens and mesenteric lymph node (MLN) cells were pressed through a $70 \mu \mathrm{m}$ filter to release leukocytes. Intestinal tissues were rinsed with phosphate-buffered saline and agitated in $1 \mathrm{mM}$ EDTA solution to disperse intestinal epithelia, followed by collagenase digestion of the remaining lamina propria cells to facilitate release of intestinal leukocytes.

Flow cytometry and intracellular cytokine staining

For detection of intracellular cytokine producing cells, cells were incubated with phorbol-12-myristate-13-acetate (PMA, $50 \mu \mathrm{g} / \mathrm{ml}$; \#P8139, Sigma-Aldrich, St. Louis, MO), calcium ionomycin (1 mg/ $\mathrm{ml}$; \#10634, Sigma-Aldrich) and brefeldin-A $(10 \mu \mathrm{g} / \mathrm{mL}$; \#B7651, Sigma-Aldrich) for $4 \mathrm{~h}$ at $37^{\circ} \mathrm{C}$. Cells were stained with antibodies against CD4 (RM4-5), CD25 (PC61.5) and fixable Live/Dead dye (Invitrogen, Carlsbad, CA) prior to permeabilization (BioLegend, San Diego, CA). Following permeabilization, cells were stained for IL-10 (JES5-16E3), IL-17 (TC11-18H10.1), IFNY (XMG1.2), and FoxP3 (FJK16S). FoxP3 staining was performed using the FoxP3 FIX/PERM buffer (BioLegend). Cells were washed and fixed with $2 \%$ paraformaldehyde and analyzed using the FACS ${ }^{\oplus}$ Cantoll system (BD Biosciences). Post-analyses were performed using FLOWJo software (Tree Star Inc, Ashland, OR).

RNA isolation, CDNA synthesis, and real-time PCR

lleal tissue segments were snap frozen in liquid nitrogen prior to homogenization and RNA isolation using the RNeasy isolation kit (Qiagen, Valencia, CA). Freshly isolated $\mathrm{CD} 4^{+} \mathrm{CD} 25^{+}$from WT and $\mathrm{TNF}^{\triangle \mathrm{ARE} /+}$ mice were purified by magnetic selection prior to RNA isolation. Synthesis of cDNA was performed using Superscript III cDNA synthesis kit (Invitrogen). Expression analysis was performed using Taqman (ThermoFisher, Waltham, MA) assays for FoxP3 (Mm00475162_m1), CD4 (Mm00442754_m1), and IL-10 (Mm00439614_m1) multiplexed with the endogenous 18S control (Eukaryotic 18S rRNA).

Jurkat T cells were harvested in RLT buffer and RNA extracted using RNeasy columns (Qiagen) prior to CDNA synthesis using miScript II RT Kit (Qiagen). MiRNA quantification for miR-106a, RNU6-2, and SNORD68 were performed using miScript Primer 
Assays (Qiagen) with analysis performed on the $A B 7300$ real-time PCR system (Applied Biosystems, Foster City, CA). For multiplex miRNA analysis, isolated Tregs from WT/FoxP3-GFP and TNF ${ }^{\triangle A R E /}$ +/FoxP3-GFP reporter mice were obtained by pre-enrichment using an EasySep CD4 negative selection kit (STEMCELL) followed by flow sorting for $\mathrm{CD}^{+}$FoxP3-GFP ${ }^{+}$cells.

\section{T cell suppression assay}

Treg-mediated suppression was measured as previously described. ${ }^{37}$ Briefly, $\mathrm{CD} 4{ }^{+} \mathrm{CD} 25^{+}$Tregs were isolated by negative selection of $\mathrm{CD}^{+}{ }^{+} \mathrm{T}$ cells, followed by positive selection of $\mathrm{CD} 25^{+}$ cells using the EasySep Treg isolation kit (STEMCELL). Treg frequency was previously confirmed by flow cytometry with $\sim 85 \%$ of enriched $\mathrm{CD} 4{ }^{+} \mathrm{CD} 25^{+}$expressing FoxP3. ${ }^{38} \mathrm{CD} 4^{+} \mathrm{CD} 25^{\mathrm{Neg}}$ effector T cells were labeled with CellTrace Violet (Invitrogen) according to manufacturer's instructions prior to stimulation with anti-CD3 $\mathrm{mAb}(1 \mu \mathrm{g} / \mathrm{ml} ; 145-2 \mathrm{C} 11$, BioLegend) in the presence of irradiated syngeneic APC to allow for fluorescent monitoring of cell proliferation. Proliferating cells were co-cultured with varying ratios of converted $\mathrm{CD} 4^{+} \mathrm{CD} 25^{+}$Treg from WT or TNF ${ }^{\triangle A R E} /++$ which had been transduced with either miRZIP000 or miRZIP106a to determine the impact of selective inhibition of miR-106a on Treg suppressive function. Anti-IL-10R (10 $\mu \mathrm{g} / \mathrm{ml} ; 1 \mathrm{~B} 1.3 \mathrm{a}$, BioLegend) or recombinant IL-10 (10 ng/ml; Peprotech, Rocky Hill, NJ) were added to culture conditions as indicated.

\section{Cytokine production assays}

Cytokine detection was performed on isolated cells by stimulating cells for $24 \mathrm{~h}$ with anti-CD3/CD28 antibodies $(1 \mu \mathrm{g} / \mathrm{ml} ; 37.51$, BioLegend) and snap freezing cell supernatants for subsequent analysis. Anti-inflammatory cytokine IL-10 concentration was measured using the Mouse IL-10 ELISA Ready-SET-Go! Kit (eBioscience, San Diego, CA).

T cell conversion assays

Magnetically separated $\mathrm{CD} 4{ }^{+} \mathrm{CD} 25^{\mathrm{Neg}}$ splenocytes were cultured for $72 \mathrm{~h}$ in 96-well round-bottom plates stimulated with platebound anti-CD3 $(1 \mu \mathrm{g} / \mathrm{ml})$, soluble anti-CD28 $(1 \mu \mathrm{g} / \mathrm{ml})$, recombinant murine IL-2 $(10 \mathrm{ng} / \mathrm{ml}$; Peprotech) and without (Th0 conditions) or with ( $\operatorname{Tr} 1$ conditions) recombinant human TGF $\beta$ $(10 \mathrm{ng} / \mathrm{ml} ; \mathrm{R} \& D$ systems, Minneapolis, MN). Cells were then restimulated for $4 \mathrm{~h}$ with $\mathrm{PMA} /$ /onomycin/brefeldin-A prior to fixation and permeabilization using the FoxP3 staining kit (eBioscience) according to manufacturer's instructions and staining for IFNy, IL-17, IL-10, and FoxP3.

\section{Luciferase assays}

Early passage Jurkat cells were plated at $0.5 \times 10^{6}$ cells/well in a 6well format and transfected using Lipofectamine LTX (ThermoFisher) with $2.5 \mu \mathrm{g}$ of DNA/well of miR-106a promoter luciferase/ reporter construct along with 50 ng of TK Renilla control reporter vector. $24 \mathrm{~h}$ post transfection cells were replated to $2.5 \times 10^{5}$ cells/ well in a 96-well plate and treated with increasing concentrations of recombinant human TNFa or TGF $\beta$ for $6 \mathrm{~h}$. Cells were then centrifuged, supernatants removed, and cells lysed in $25 \mu \mathrm{l}$ of passive lysis buffer (Promega, Madison, WI) prior to measuring luciferase activity on a GloMax ${ }^{\circledR}$-Multi Microplate Multimode Reader (Promega). The full and truncated miR-106a promoter constructs incorporating the human chromosome X:133137287 to 133138287 region were synthesized by GenScript (Piscataway, NJ) based on predicted sequences described previously. ${ }^{23}$

\section{Human $\mathrm{CD}^{+} \mathrm{T}$ cell assays}

Peripheral blood mononuclear cells were obtained from healthy donors using CPT tubes (BD Biosciences) according to manufacturer's instructions. Frozen PBMC were rapidly thawed and rested for $2 \mathrm{~h}$ in serum-free X-VIVO media (Lonza, Allendale, $\mathrm{NJ}$ ) at $37^{\circ} \mathrm{C}$ prior to treatment with recombinant human $\mathrm{TNFa}(10 \mathrm{ng} / \mathrm{ml}$,
eBioscience) for $6 \mathrm{~h}$. Unfractionated RNA was isolated using mirVana miRNA isolation kit (Invitrogen), followed by targetspecific cDNA synthesis using the TaqMan MicroRNA Reverse Transcription kit (Applied Biosystems) and expression analysis performed using TaqMan miRNA probe sets expressed relative to the endogenous control RPL21.

\section{Lentiviral transduction}

Lentiviral antagomirs to inhibit miR-106a (miRZIP106a) or scrambled control vector (miRZIP000) were generated according to manufacturer's instructions (System Biosciences, Palo Alto, CA). Briefly viral particles were generated in HEK293TN cells transfected with miRZIP vectors and pPackH1 packaging mix containing pVSV-G, pPACKH1-GAG, and pPACK-H1-REV plasmids. Viral supernatant was concentrated using PEG-it virus precipitation solution. High titer virus was then incubated with isolated $\mathrm{CD} 4{ }^{+} \mathrm{CD} 25^{\mathrm{Neg}} \mathrm{T}$ cells, spinoculated for $2 \mathrm{~h}$ at $300 \times \mathrm{g}$ on day 0 and day 1 with polybrene $(4 \mathrm{mg} / \mathrm{ml})$ and cultured for $72 \mathrm{~h}$ in the presence of TGF $\beta(10 \mathrm{ng} / \mathrm{ml})$, IL-2 (5units $/ \mathrm{ml})$, soluble antiCD28 antibody $(1 \mu \mathrm{g} / \mathrm{ml})$, and plate-bound anti-CD3 antibody (1 $\mu \mathrm{g} / \mathrm{ml}$ ) to promote Treg induction based on a previously published method. ${ }^{39}$ Suppressive function of transfected cells was assayed as previously described.

Competitive homing assays

Magnetically separated $\mathrm{CD}^{+}{ }^{+}$splenocytes were isolated from WT and $\mathrm{miR}-106 \mathrm{a}^{-/}$donors, and labeled with either CellTrace or Calcein Red-orange (Invitrogen) according to manufacturer's instructions. Cells were then recounted and mixed in a 1:1 ratio prior to retro-orbital injection of $5 \times 10^{6}$ cells/mouse. Mice were killed after $18 \mathrm{~h}$ and expression of labeled cells identified by flow cytometry. Dye-swap experiments were performed to exclude an impact of either dye on gut homing. Results were expressed relative to injection fraction.

Statistics

Statistical analyzes were performed using the Student's $t$ test or 2way ANOVA with Prism Data Analysis software (GraphPad Software, La Jolla, CA). Data were expressed as mean \pm standard error of the mean (SEM). Statistical significance was set at a $P<$ 0.05 .

Study approval

Experimental animal protocols were carried out in accordance with the AAALAC-accredited Institutional Animal Care and Use Committee (IACUC) at the University of Colorado School of Medicine and in compliance with recommendations in the Guide for the Care and Use of Laboratory Animals, Animal Welfare Act and PHS Policy. De-identified healthy human patient samples were collected and used in accordance with Colorado Multiple Institutional Review Board approval COMIRB \#00-510.

\section{AUTHOR CONTRIBUTIONS}

All authors provided important input to experimental design, critical review, and final approval of the manuscript. R.H.H., M.R.S., and C.B.C. co-wrote the manuscript and corrections, and performed flow and animal experiments. A.A.J. and M.R.S. performed suppression assays. M.R.S. and C.B.C. performed conversion assays. M.E.L. and C.B.C. performed PCR analysis and luciferase assays. C.M.A. assisted with luciferase assays, proofing the manuscript, and experimental design. P.J. provided blinded histological evaluation of intestinal inflammation. E.d.Z. provided guidance with experimental design, data interpretation, and manuscript editing

\section{ADDITIONAL INFORMATION}

The online version of this article (https://doi.org/10.1038/s41385-018-0091-7) contains supplementary material, which is available to authorized users.

Competing interests: The authors declare no competing interests. 


\section{REFERENCES}

1. Kaplan, G. G. The global burden of IBD: from 2015 to 2025. Nat. Rev. Gastroenterol. Hepatol. 12, 720-727 (2015).

2. Reinisch, W. et al. Adalimumab for induction of clinical remission in moderately to severely active ulcerative colitis: results of a randomised controlled trial. Gut 60, 780-787 (2011).

3. Lichtenstein, G. R. et al. Continuous therapy with certolizumab pegol maintains remission of patients with Crohn's disease for up to 18 months. Clin. Gastroenterol. Hepatol. 8, 600-609 (2010).

4. Strober, W., Fuss, I. J. \& Blumberg, R. S. The immunology of mucosal models of inflammation. Annu. Rev. Immunol. 20, 495-549 (2002).

5. Groux, H. et al. A CD4+T-cell subset inhibits antigen-specific T-cell responses and prevents colitis. Nature 389, 737-742 (1997).

6. Vignali, D. A. A., Collison, L. W. \& Workman, C. J. How regulatory T cells work. Nat. Rev. Immunol. 8, 523-532 (2008).

7. Kühn, R., Löhler, J., Rennick, D., Rajewsky, K. \& Müller, W. Interleukin-10-deficient mice develop chronic enterocolitis. Cell 75, 263-274 (1993).

8. Glocker, E.-O. et al. Inflammatory bowel disease and mutations affecting the interleukin-10 receptor. N. Engl. J. Med. 361, 2033-2045 (2009).

9. Reikvam, D. H. et al. Increase of regulatory T cells in ileal mucosa of untreated pediatric Crohn's disease patients. Scand. J. Gastroenterol. 46, 550-560 (2011).

10. Boschetti, G. et al. Therapy with anti-TNFa antibody enhances number and function of Foxp3(+) regulatory T cells in inflammatory bowel diseases. Inflamm. Bowel Dis. 17, 160-170 (2011).

11. Collins, C. B. et al. CD44 deficiency attenuates chronic murine ileitis. Gastroenterology 135, 1993-2002 (2008).

12. Kontoyiannis, D., Pasparakis, M., Pizarro, T. T., Cominelli, F. \& Kollias, G. Impaired on/off regulation of TNF biosynthesis in mice lacking TNF AU-rich elements: implications for joint and gut-associated immunopathologies. Immunity 10, 387-398 (1999).

13. Wu, F. et al. MicroRNAs are differentially expressed in ulcerative colitis and alter expression of macrophage inflammatory peptide-2 alpha. Gastroenterology 135, 1624-1635.e24 (2008).

14. Sharma, A. et al. Posttranscriptional regulation of interleukin-10 expression by hsa-miR-106a. Proc. Natl Acad. Sci. USA 106, 5761-5766 (2009).

15. Luck, M. E., Muljo, S. A. \& Collins, C. B. Prospects for therapeutic targeting of microRNAs in human immunological diseases. J. Immunol. 194, 5047-5052 (2015).

16. Omidbakhsh, A., Saeedi, M., Khoshnia, M., Marjani, A. \& Hakimi, S. Micro-RNAs $-106 a$ and $-362-3 p$ in peripheral blood of inflammatory bowel disease patients. Open Biochem. J. 12, 78-86 (2018).

17. Collins, C. B. et al. Retinoic acid attenuates ileitis by restoring the balance between T-helper 17 and T regulatory cells. Gastroenterology 141, 1821-1831 (2011).

18. Kamanaka, M. et al. Expression of interleukin-10 in intestinal lymphocytes detected by an interleukin-10 reporter knockin tiger mouse. Immunity 25, 941-952 (2006).

19. Li, C., Feng, Y., Coukos, G. \& Zhang, L. Therapeutic microRNA strategies in human cancer. AAPS J. 11, 747-757 (2009).

20. Suárez, Y., Wang, C., Manes, T. D. \& Pober, J. S. Cutting edge: TNF-induced microRNAs regulate TNF-induced expression of E-selectin and intercellular adhesion molecule-1 on human endothelial cells: feedback control of inflammation. J. Immunol. 184, 21-25 (2010).

21. Cobb, B. S. et al. A role for Dicer in immune regulation. J. Exp. Med. 203, 2519-2527 (2006).

22. Wu, F. et al. Identification of microRNAs associated with ileal and colonic Crohn's disease. Inflamm. Bowel Dis. 16, 1729-1738 (2010).

23. Fujita, S. \& Iba, H. Putative promoter regions of miRNA genes involved in evolutionarily conserved regulatory systems among vertebrates. Bioinformatics 24, 303-308 (2008).

24. Mercadante, E. R. \& Lorenz, U. M. Breaking free of control: how conventional T cells overcome regulatory T cell suppression. Front. Immunol. 7, 193 (2016).

25. Li, Z. et al. Reciprocal changes of Foxp3 expression in blood and intestinal mucosa in IBD patients responding to infliximab. Inflamm. Bowel Dis. 16, 1299-1310 (2010).

26. Li, Z. et al. Restoration of Foxp3 + regulatory T-cell subsets and Foxp3-type 1 regulatory-like $\mathrm{T}$ cells in inflammatory bowel diseases during anti-tumor necrosis factor therapy. Inflamm. Bowel Dis. 21, 2418-2428 (2015).

27. Murray, P. J., Wang, L., Onufryk, C., Tepper, R. I. \& Young, R. A. T cell-derived IL-10 antagonizes macrophage function in mycobacterial infection. J. Immunol. 158, 315-321 (1997).

28. Collins, C. B. et al. C/EBP $\beta$ deletion promotes expansion of poorly functional intestinal regulatory T cells. J. Crohns. Colitis https://doi.org/10.1093/ecco-jcc/ jjy105 (2018)

29. Hampe, J. et al. Association between insertion mutation in NOD2 gene and Crohn's disease in German and British populations. Lancet 357, 1925-1928 (2001).

30. Saraiva, M. \& O'Garra, A. The regulation of IL-10 production by immune cells. Nat. Rev. Immunol. 10, 170-181 (2010).

31. Bronevetsky, Y. et al. T cell activation induces proteasomal degradation of Argonaute and rapid remodeling of the microRNA repertoire. J. Exp. Med. 210, 417-432 (2013).

32. Veltkamp, C. et al. Apoptosis of regulatory $\mathrm{T}$ lymphocytes is increased in chronic inflammatory bowel disease and reversed by anti-TNFa treatment. Gut $\mathbf{6 0}$, 1345-1353 (2011).

33. Hovhannisyan, Z., Treatman, J., Littman, D. R. \& Mayer, L. Characterization of interleukin-17-producing regulatory $T$ cells in inflamed intestinal mucosa from patients with inflammatory bowel diseases. Gastroenterology 140, 957-965 (2011).

34. Powrie, F. et al. Inhibition of Thl responses prevents inflammatory bowel disease in scid mice reconstituted with CD45RB hi CD4 + T cells. Immunity 1, 553-562 (1994).

35. Pan, Y.-J. et al. MiR-106a-5p inhibits the cell migration and invasion of renal cell carcinoma through targeting PAK5. Cell Death Dis. 8, e3155 (2017).

36. Collins, C. B. et al. Alpha-1-antitrypsin therapy ameliorates acute colitis and chronic murine ileitis. Inflamm. Bowel Dis. 19, 1964-1973 (2013).

37. Collins, C. B. et al. Inhibition of N-terminal ATPase on HSP90 attenuates colitis through enhanced Treg function. Mucosal Immunol. 6, 960-971 (2013).

38. Jones, A. et al. Cannabinoid receptor- 2 ameliorates inflammation in murine model of Crohn's disease. J. Crohns. Colitis 11, 1369-1380 (2017).

39. Geng, X., Doitsh, G., Yang, Z., Galloway, N. L. K. \& Greene, W. C. Efficient delivery of lentiviral vectors into resting human CD4 T cells. Gene Ther. 21, 444-449 (2014). 